УДК $004.942+76$

\author{
А. В. МанАе $\mathrm{e}^{1,2}$, Ю. С. Боярінова ${ }^{1,2}$, Я. О. Каміновський ${ }^{1}$ \\ ${ }^{1}$ Інститут проблем реєстрації інформації НАН України \\ вул. М. Шпака, 2, 03113 Київ, Україна \\ ${ }^{2}$ Національний технічний університет України \\ «Київський політехнічний інститут імені Ігоря Сікорського» \\ Проспект Перемоги, 37, 03113 Київ, Україна
}

\title{
Модель динамічної мережі на базі застосування гіперкомплексних числових систем
}

\begin{abstract}
Запропоновано використання гіперкомплексних числових систем для опису динамічної мережі та різноманітних впливів у ичих мережах. Для спрощення обчислень запропоновано використовувати ізоморфні гіперкомплексні числові системи, таблиця Келі однієї з яких має діагональний вигляд.
\end{abstract}

Ключові слова: складні системи, складні мережі, гіперкомплексна числова система, ізоморфізм гіперкомплексних систем, модель впливу.

\section{Вступ}

В останні роки отримав розвиток напрям дослідження мереж, в яких зв'язки у змістовному плані відповідають взаємним впливам вузлів. Дослідженню таких складних мереж (Complex Networks) присвячено багато праць [1-3], але найчастіше вони відносяться до розповсюдження одного виду активності (впливу). В той же час уже з'являються дослідження, що пропонують розглядати декілька характеристик впливу [4-6]. Зокрема, розробляються та досліджуються різноманітні математичні моделі: моделі з порогами, моделі незалежних каскадів, моделі розповсюдження епідемій, моделі марковських процесів та ін. [7-11].

У цій роботі пропонується застосовувати гіперкомплексні числові системи, які $є$ математичним апаратом, що дозволяє моделювати деякі мережеві задачі та вирішувати їх на новому рівні [12].

\section{Постановка задачі}

Метою даної роботи є моделювання розповсюдження декількох характеристик впливів на вузли складної мережі із застосуванням апарату гіперкомплексних числових систем (ГЧС).

(C) А. В. Аанде, Ю. Є. Боярінова, Я. О. Каліновський 


\section{Гіперкомплексна мережева модель розповсюдження декімькох видів активності}

Розглянемо мережі, де ребра відповідають взаємним впливам вузлів. Зазвичай розглядаються динамічні мережеві моделі, засновані на розповсюдженні одного виду активності. Запропонована модель, навпаки, базується на мережах, в яких передбачено багато видів активності.

Нехай складна мережа - це граф, який складається з $N$ вузлів, між якими $\epsilon$ зв'язки між вузлами $i$ та $j$ (ребра) з вагою $L_{i, j}, i, j=1, \ldots, N$. Якщо ребро між вузлами відсутнє, то враховуємо вагу зв'язку $L_{i, j}=0$. У загальному вигляді складна система виглядає, як зображено на рис. 1.

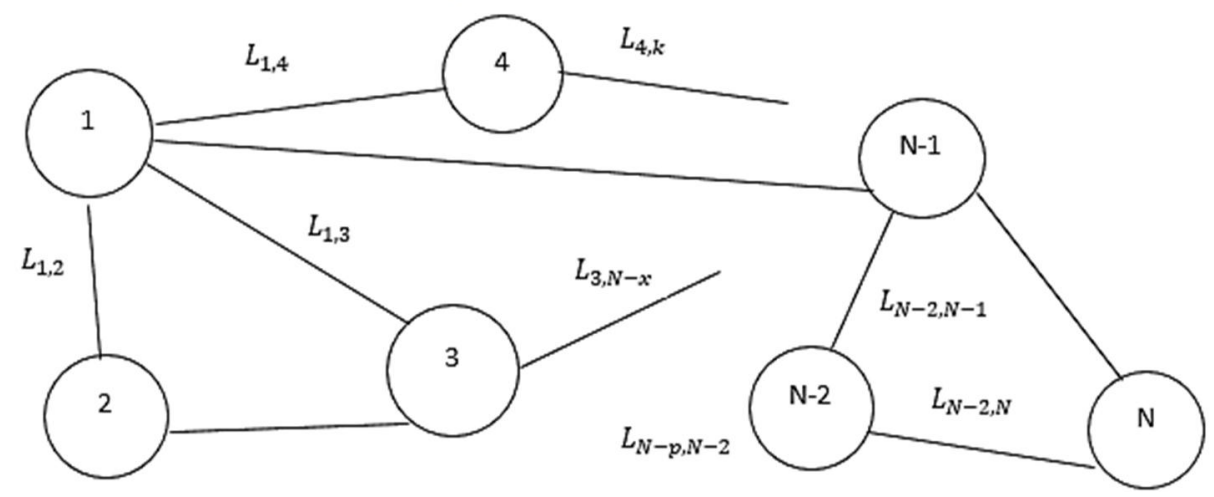

Рис. 1. Загальний вигляд складної системи

У запропонованій моделі розглянемо таку

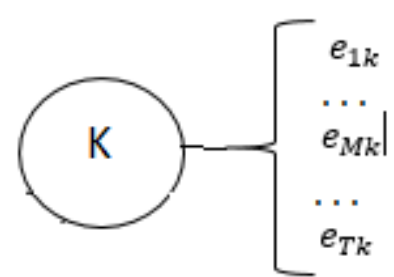

Рис. 2. Властивості одного вузла можливість, що в кожному вузлі є декілька властивостей, які можуть бути описані гіперкомплексною числовою системою вимірності $T$ у загальному випадку (рис. 2).

Вплив властивостей одного вузла на інший може відбуватися за таблицею Келі деякої ГЧС (рис. 3).

\begin{tabular}{|c|c|c|c|c|}
\hline & $e_{1}$ & $e_{2}$ & $\cdots$ & $e_{T}$ \\
\hline$e_{1}$ & $\sum_{k=1}^{T} a_{1}^{1} e_{k}$ & $\sum_{k=1}^{T} a_{1}^{2} e_{k}$ & & $\sum_{k=1}^{T} a_{1}^{T} e_{k}$ \\
\hline$e_{2}$ & $\sum_{k=1}^{T} a_{2}^{1} e_{k}$ & $\sum_{k=1}^{T} a_{2}^{2} e_{k}$ & & $\sum_{k=1}^{T} a_{2}^{T} e_{k}$ \\
\hline$e_{T}$ & $\sum_{k=1}^{T} a_{T}^{1} e_{k}$ & $\sum_{k=1}^{T} a_{T}^{2} e_{k}$ & & $\sum_{k=1}^{T} a_{T}^{T} e_{k}$ \\
\hline
\end{tabular}

Рис. 3. Загальний вигляд таблиці Келі 
Розглянемо випадок, коли вузол має тільки дві властивості $T=2$. Тоді таблиця Келі складається з чотирьох клітинок $\left(T^{2}=4\right)$ :

\begin{tabular}{|c|cc|}
\hline$\Gamma(e, 2)$ & $e_{1}$ & $e_{2}$ \\
\hline$e_{1}$ & $a_{1} e_{1}+a_{2} e_{2}$ & $b_{1} e_{1}+b_{2} e_{2}$ \\
$e_{2}$ & $b_{1} e_{1}+b_{2} e_{2}$ & $c_{1} e_{1}+c_{2} e_{2}$ \\
\hline
\end{tabular}

У таблиці Келі (1) усі структурні константи — дійсні числа. Але не будь-яка таблиця вигляду (1) буде ГЧС. Для цього вона повинна мати одиничний елемент $\varepsilon$.

Якщо

$$
\varepsilon=x_{1} e_{1}+x_{2} e_{2}
$$

то наявність одиничного елемента буде вимагати існування нетривіального дійсного рішення гіперкомплексного рівняння

$$
W \varepsilon=W,
$$

де $W=w_{1} e_{1}+w_{2} e_{2} \in \Gamma(e, 2)$.

Рівняння (3) перетворюється у систему лінійних дійсних рівнянь

$$
\left\{\begin{array}{l}
\left(w_{1} a_{1}+w_{2} b_{1}\right) x_{1}+\left(w_{1} b_{1}+w_{2} c_{1}\right) x_{2}=w_{1}, \\
\left(w_{1} a_{2}+w_{2} b_{2}\right) x_{1}+\left(w_{1} b_{2}+w_{2} c_{2}\right) x_{2}=w_{2},
\end{array}\right.
$$

звідки

$$
\begin{aligned}
& x_{1}=\frac{b_{2} w_{1}^{2}+\left(c_{2}-b_{1}\right) w_{1} w_{2}+c_{1} w_{2}^{2}}{\left(a_{1} b_{2}-a_{2} b_{1}\right) w_{1}^{2}+\left(a_{1} c_{2}-a_{2} c_{1}\right) w_{1} w_{2}+\left(b_{1} c_{2}-b_{2} c_{1}\right) w_{2}^{2}}, \\
& x_{2}=\frac{-a_{2} w_{1}^{2}+\left(a_{1}-b_{2}\right) w_{1} w_{2}+b_{1} w_{2}^{2}}{\left(a_{1} b_{2}-a_{2} b_{1}\right) w_{1}^{2}+\left(a_{1} c_{2}-a_{2} c_{1}\right) w_{1} w_{2}+\left(b_{1} c_{2}-b_{2} c_{1}\right) w_{2}^{2}} .
\end{aligned}
$$

Як бачимо з (5), компоненти одиничного елемента залежать не тільки від структурних констант гіперкомплексної системи $\Gamma(e, 2)$, що, в загальному випадку, не протирічить визначенню одиничного елемента, але і від компонент коефіцієнта $W$ рівняння визначення одиничного елемента (3), чого не повинно бути. Сдиний засіб виключення залежності виразу (5) від компонент числа $W \in$ пропорційність коефіцієнтів квадратичних форм, що стоять у чисельнику та знаменнику (5):

$$
\begin{aligned}
& \frac{b_{2}}{a_{1} b_{2}-a_{2} b_{1}}=\frac{c_{2}-b_{1}}{a_{1} c_{2}-a_{2} c_{1}}=\frac{-c_{1}}{b_{1} c_{2}-b_{2} c_{1}}, \\
& \frac{-a_{2}}{a_{1} b_{2}-a_{2} b_{1}}=\frac{a_{1}-b_{2}}{a_{1} c_{2}-a_{2} c_{1}}=\frac{b_{1}}{b_{1} c_{2}-b_{2} c_{1}} .
\end{aligned}
$$

Вирази (6) і (7) являють собою систему з чотирьох незалежних рівнянь, які визначають вимоги до структурних констант для того, щоб ГЧС (1) мала одиничний елемент. 
Система чотирьох рівнянь (6), (7) має шість невідомих структурних констант. Будемо вважати константи $c_{1}, c_{2}$ вільними, тому що ГЧС 3 такими структурними константами вже відомі.

Тоді система (6), (7) має два розв'язки.

1-й розв'язок:

$$
a_{1} \in R, \quad a_{2}=0, \quad b_{1}=0, \quad b_{2}=a_{1}, \quad c_{1}, c_{2} \in R .
$$

Це рішення приводить до системи

\begin{tabular}{|c|cc|}
\hline$\Gamma_{1}(e, 2)$ & $e_{1}$ & $e_{2}$ \\
\hline$e_{1}$ & $a_{1} e_{1}$ & $a_{1} e_{2}$ \\
$e_{2}$ & $a_{1} e_{2}$ & $c_{1} e_{1}+c_{2} e_{2}$ \\
\hline
\end{tabular}

Система $\Gamma_{1}(e, 2)$ має одиничний елемент $\varepsilon$, який не $\epsilon$ елементом базису ГЧС:

$$
\varepsilon=\frac{1}{a_{1}} e_{1}
$$

Підтвердженням цього є наступне:

$$
W \varepsilon=\left(w_{1} e_{1}+w_{2} e_{2}\right) \frac{1}{a_{1}} e_{1}=w_{1} \frac{1}{a_{1}} a_{1} e_{1}+w_{2} \frac{1}{a_{1}} a_{1} e_{2}=w_{1} e_{1}+w_{2} e_{2}=W .
$$

Лінійним невиродженим перетворенням базису $e=\left\{e_{1}, e_{2}\right\}$ можна перейти до нового базису

$$
f_{1}=\frac{1}{a_{1}} e_{1}, f_{2}=e_{2}
$$

що дає ГЧС $\Gamma_{2}(f, 2)$, яка ізоморфна $\Gamma_{1}(e, 2)$ :

\begin{tabular}{|c|cc|}
\hline$\Gamma_{2}(f, 2)$ & $f_{1}$ & $f_{2}$ \\
\hline$f_{1}$ & $f_{1}$ & $f_{2}$ \\
$f_{2}$ & $f_{2}$ & $a_{1} c_{1} f_{1}+c_{2} f_{2}$ \\
\hline
\end{tabular}

Система $\Gamma_{2}(f, 2)$ - це ГЧС, яка може бути ізоморфною системам $Q C, Q D$ або $Q W[13,15]$.

Залежно від знаку виразу

$$
a_{1} c_{1}+\frac{c_{2}^{2}}{4}
$$

вона ізоморфна одній із «класичних» систем: комплексній $C(e, 2)$, дуальній $D(e, 2)$, двійній $W(e, 2)$. 
2-й розв'язок:

$$
\begin{aligned}
& b_{1} \in R, \quad b_{2}=c_{2}-b_{1}, \\
& a_{1}=\frac{b_{1}^{2}-\left(b_{1}-c_{1}\right)\left(b_{1}-c_{2}\right)}{c_{1}}, \quad a_{2}=-\frac{b_{1}\left(b_{1}-c_{2}\right)}{c_{1}}, \\
& c_{1} \in R \backslash\{0\}, \quad c_{2} \in R .
\end{aligned}
$$

Цей розв'язок приводить до такої системи:

\begin{tabular}{|c|cc|}
\hline$\Gamma_{3}(e, 2)$ & $e_{1}$ & $e_{2}$ \\
\hline$e_{1}$ & $\frac{b_{1}^{2}-\left(b_{1}-c_{1}\right)\left(b_{1}-c_{2}\right)}{c_{1}} e_{1}-\frac{b_{1}\left(b_{1}-c_{2}\right)}{c_{1}} e_{2}$ & $b_{1} e_{1}+\left(c_{2}-b_{1}\right) e_{2}$ \\
$e_{2}$ & $b_{1} e_{1}+\left(c_{2}-b_{1}\right) e_{2}$ & $c_{1} e_{1}+c_{2} e_{2}$ \\
\hline
\end{tabular}

ГЧС $\Gamma_{3}(e, 2)$ має одиничний елемент:

$$
\varepsilon=\frac{1}{c_{1} c_{2}-b_{1}\left(c_{1}+c_{2}\right)}\left(c_{1} e_{1}-b_{1} e_{2}\right) .
$$

При значеннях структурних констант

$$
b_{1}=0, \quad b_{2}=c_{2}, \quad a_{1}=c_{2}, \quad a_{2}=0
$$

система (16) $\Gamma_{3}(e, 2)$ перетворюється в ізоморфну їй систему

\begin{tabular}{|c|cc|}
\hline$\Gamma_{4}(e, 2)$ & $e_{1}$ & $e_{2}$ \\
\hline$e_{1}$ & $c_{2} e_{1}$ & $c_{2} e_{2}$ \\
$e_{2}$ & $c_{2} e_{2}$ & $c_{1} e_{1}+c_{2} e_{2}$ \\
\hline
\end{tabular}

3 одиничним елементом

$$
\varepsilon=\frac{1}{c_{2}} e_{1}
$$

Лінійним невиродженим перетворенням базису $e=\left\{e_{1}, e_{2}\right\}$ можна перейти до нового базису

$$
\begin{gathered}
f_{1}=\frac{1}{c_{2}} e_{1}, \\
f_{2}=e_{2},
\end{gathered}
$$

що дає ГЧС $\Gamma_{5}(f, 2)$, яка ізоморфна $\Gamma_{4}(e, 2)$ :

\begin{tabular}{|c|cc|}
\hline$\Gamma_{5}(f, 2)$ & $f_{1}$ & $f_{2}$ \\
\hline$f_{1}$ & $f_{1}$ & $f_{2}$ \\
$f_{2}$ & $f_{2}$ & $c_{1} c_{2} f_{1}+c_{2} f_{2}$ \\
\hline
\end{tabular}


Система $\Gamma_{5}(f, 2)$ - це система, яка може бути ізоморфною системам $Q C$, $Q D$ та $Q W$. Залежно від знаку виразу:

$$
c_{1} c_{2}+\frac{c_{2}^{2}}{4}
$$

Система $\Gamma_{5}(f, 2)$ ізоморфна одній із «класичних» систем: комплексній $C(e, 2)$, дуальній $D(e, 2)$, двійній $W(e, 2)$.

Таким чином, розглядаючи вплив одного вузла на інший з двома властивостями, можна використовувати ГЧС, таблиця Келі якої має вигляд (22)

\section{Основні відомості про пакет гіперкомплексних обчислень}

Основною трудністю виконання аналітичних операцій з гіперкомплексними числами є їхня багатовимірність і пов'язана з цим фактом громіздкість в аналітичному вигляді виразів від багатовимірних гіперкомплексних чисел, таких як добуток, корені рівнянь, норми та ін. Виконання такого аналізу «вручну» на папері 3 високим ступенем імовірності приводить до виникнення помилок різного типу. Щоб уникнути цього треба використовувати методи та засоби автоматизації аналітичних обчислень з гіперкомплексними числами. Ці засоби являють собою пакет програм і процедур, створених на основі СКА Maple [14, 16].

Так як система комп'ютерної алгебри Марle дозволяє створювати спеціалізовані пакети різних обчислювальних процедур, то програмний комплекс гіперкомплексні обчислень (надалі - ПКГО) являє собою пакет, що має свій ідентифікатор. ПКГО можна викликати, приєднувати до програми та транспортувати на інші комп'ютери. 3 процедур ПКГВ можна формувати програми обчислень, використовуючи засоби алгоритмічної мови Maple.

Багато уваги при розробці ПКГО було приділено способам і структурам представлення даних. Як було зазначено вище, ПКГО призначений для оперування 3 даними в гіперкомплексному вигляді. Як відомо, загальний вигляд гіперкомплексного числа такий:

$$
A=a_{1} e_{1}+a_{2} e_{2}+\ldots+a_{n} e_{n},
$$

де $n$ - вимірність ГЧС; $a_{i}$ — алгебраїчні вирази; $e_{i}$ — елементи базису ГЧС («уявні одиниці»).

Таку форму гіперкомплексного числа будемо називати натуральною. Як показує досвід, оперувати з гіперкомплексними числами в натуральній формі досить незручно. Це пов’язано з тим, що різні операції виконуються з коефіцієнтами при базисних елементах, які потрібно виділяти й ідентифікувати.

У той же час, у системі Maple є засоби, що дозволяють позбутися цих і багатьох інших незручностей, що пов'язані з використанням натуральної форми подання гіперкомплексних чисел. Справа в тому, що в натуральній формі представлення гіперкомплексних чисел важливі тільки коефіцієнти при елементах базису і їхній порядковий номер у зображенні гіперкомплексного числа, тобто гіперкомплексні числа можна представити у вигляді вектора. Однак векторно-матрична форма не підходить 3 огляду на те, що компоненти матриціта вектора повинні бути од- 
нотипними. У той же час у системі Maple $є$ така форма представлення даних як список - list - упорядкований набір різнотипних даних. Для оперування з даними у форматі списків у Мaple існують численні команди, які дозволяють задавати список, визначати довжину списку, складати два списки однакової довжини, визначати член списку за його порядковим номером у списку, множити всі члени списку на будь-який вираз тощо. Подання гіперкомплексних чисел у вигляді списку називається списочним або внутрішнім поданням гіперкомплексних чисел. Таким чином, будемо користуватися представленням:

$$
A=\left[a_{1}, a_{2}, \ldots, a_{n}\right] .
$$

Тоді сума двох чисел буде визначатися дуже просто:

$$
C=A+B=\left[a_{1}, \ldots, a_{n}\right]+\left[b_{1}, \ldots, b_{n}\right]=\left[a_{1}+b_{1}, \ldots, a_{n}+b_{n}\right],
$$

тобто приведення подібних символьних коефіцієнтів відповідно до їхніх порядкових номерів у числах виконується автоматичними внутрішніми засобами Maple.

Таким чином, представлення гіперкомплексних чисел у форматі списків значно спрощує розробку програмних засобів. Однак таке рішення вимагає наявності в ПКГО процедур для взаємно-зворотного перетворення натуральної і внутрішньої форм представлення гіперкомплексних чисел. Тим більше, деякі дії доцільно виконувати над числами в натуральній формі. У зв'язку з цим у багатьох процедурах ПКГО передбачається вихід у формі списку з двох елементів: перший елемент результат у списочній формі, другий - у натуральній.

Також виявилося доцільним надати списочний формат і більш складним гіперкомплексним структурам. Так, таблиця Келі множення базисних елементів представляється трирівневою списочною структурою: верхній рівень складається зі списку рядків таблиці, другий вкладений рівень - зі списку елементів таблиці, третій, найнижчий рівень - зі списку структурних констант однієї клітинки таблиці Келі.

Структурно ПКГО складається з наступних підсистем:

— алгебраїчних операцій у ГЧС;

— маніпуляції з ГЧС і таблицями Келі;

— визначення алгебраїчних характеристик гіперкомплексних виразів;

- зберігання часто вживаних виразів;

- виконання модульних операцій з гіперкомплексними виразами;

- візуалізації і сервісу.

Така структура та склад програмного комплексу гіперкомплексних символьних обчислень у середовищі Maple, як буде показано далі, дозволяє значно спростити процеси створення програмного забезпечення для математичного моделювання різних науково-технічних задач.

Усі процедури ПКГО можна використовувати при написанні програм вирішення різних задач з гіперкомплексними даними мовою програмування Maple. Для цього треба підключити до програми ПКГО відповідно до норм Maple та викликати потрібні процедури за їхніми ідентифікаторами, як це буде показано далі.

Розглянемо декілька прикладів. 


\section{3. ПрикмаАи}

Найпростіший приклад, коли система складається з трьох вузлів (рис. 4), у кожному вузлі присутні дві властивості, що відповідають ГЧС 2-ї вимірності.

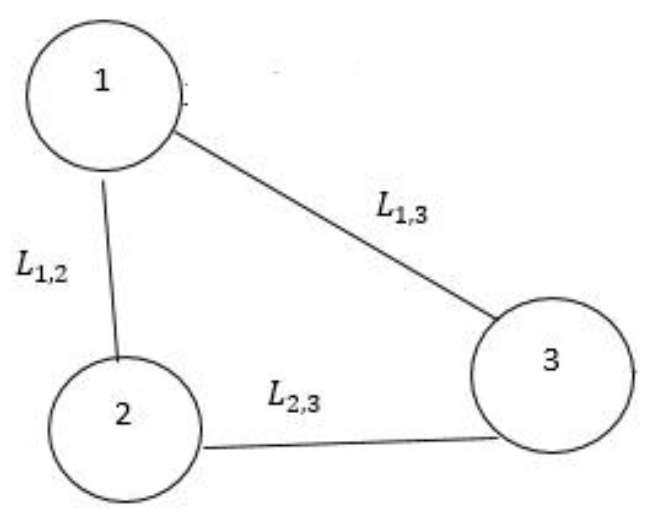

Рис. 4. Система з трьох вузлів і зв’язків

Систему рівнянь цієї моделі відповідно до п. 1 легко побудувати за допомогою засобів ПКГО. Програма цієї побудови виглядає так:

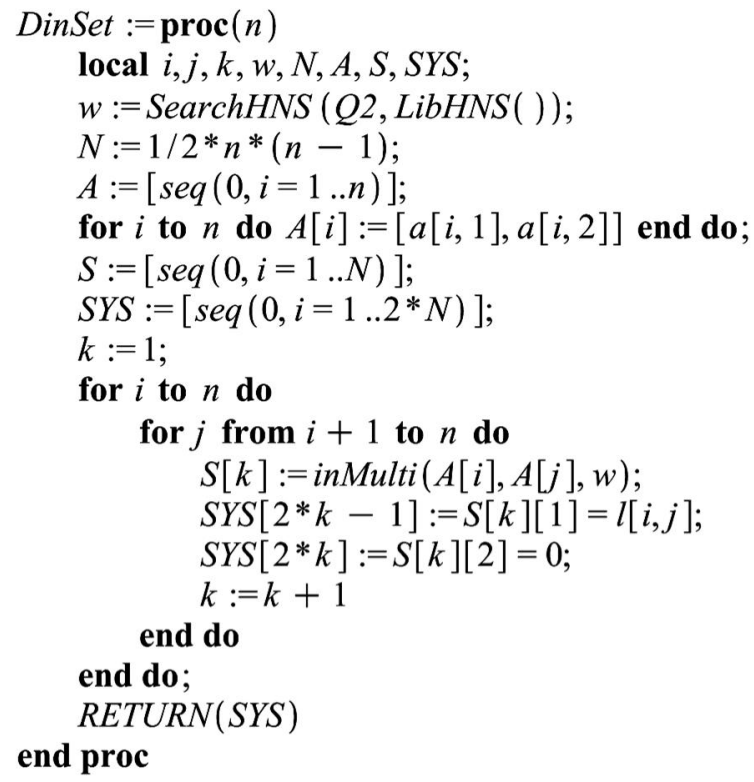

Розглянемо випадок мережі, яка складається з трьох вузлів. Система впливу вузлів будується за допомогою процедури:

$$
\begin{aligned}
& \operatorname{DinSet}(3) \\
& a_{1,1} a_{2,1}+a_{1,2} a_{2,2} p=l_{1,2}, \\
& a_{1,1} a_{2,2}+a_{1,2} a_{2,1}+a_{1,2} a_{2,2} q=0 \\
& a_{1,1} a_{3,1}+a_{1,2} a_{3,2} p=l_{1,3}, \\
& a_{1,1} a_{3,2}+a_{1,2} a_{3,1}+a_{1,2} a_{3,2} q=0
\end{aligned}
$$




$$
\begin{gathered}
a_{2,1} a_{3,1}+a_{2,2} a_{3,2} p=l_{2,3}, \\
a_{2,1} a_{3,2}+a_{2,2} a_{3,1}+a_{2,2} a_{3,2} q=0 .
\end{gathered}
$$

Як бачимо система складається з 6-ти рівнянь, невідомими в якій будуть 6 вагових коефіцієнтів $a_{i j}$, тобто список невідомих:

$$
\operatorname{var}=\left[a_{1,1}, a_{1,2}, a_{2,1}, a_{2,2}, a_{3,1}, a_{3,2}\right] .
$$

Розв'язуємо (24) в радикалах:

$$
\text { convert (solve (SYS, var), radical). }
$$

Система (24) має 2 рішення. Перше рішення

$$
\begin{gathered}
a_{1,1}=\frac{l_{1,3}}{\sqrt{\frac{l_{1,3} l_{2,3}}{l_{1,2}}}}, a_{1,2}=\mathrm{C}, \\
a_{2,1}=\frac{l_{2,3}}{\sqrt{\frac{l_{1,3} l_{2,3}}{l_{1,2}}}}, a_{2,2}=0, a_{3,1}=\sqrt{\frac{l_{1,3} l_{2,3}}{l_{1,2}}}, a_{3,2}=\mathrm{C}
\end{gathered}
$$

має нульові коефіцієнти $a_{1,2}=a_{2,2}=a_{3,2}=0$, тобто переходимо до мережі 3 дійсними параметрами.

Дослідимо друге рішення:

$$
\begin{gathered}
a_{1,1}=-\frac{\sqrt{\frac{l_{1,2} l_{2,3}}{4 p l_{1,3}+l_{1,3} q^{2}}} l_{1,3} q}{l_{2,3}}, \quad a_{1,2}=\frac{2 \sqrt{\frac{l_{1,2} l_{2,3}}{4 p l_{1,3}+l_{1,3} q^{2}}} l_{1,3}}{l_{2,3}}, \\
a_{2,1}=-\sqrt{\frac{l_{1,2} l_{2,3}}{4 p l_{1,3}+l_{1,3} q^{2}}} q, \quad a_{2,2}=2 \sqrt{\frac{l_{1,2} l_{2,3}}{4 p l_{1,3}+l_{1,3} q^{2}}}, \\
a_{3,1}=-\frac{2 l_{2,3}}{\sqrt{\frac{l_{1,2} l_{2,3}}{4 p l_{1,3}+l_{1,3} q^{2}}\left(q^{2}+4 p\right)}}, a_{3,2}=\frac{2 l_{2,3}}{\sqrt{\frac{l_{1,2} l_{2,3}}{4 p l_{1,3}+l_{1,3} q^{2}}}\left(q^{2}+4 p\right)} .
\end{gathered}
$$

Цей розв'язок залежить від параметрів $p$ та $q$, які є структурними константами ГЧС. Тобто, вибором цих параметрів можна вибирати тип вживаної ГЧС.

Нехай $p=1, q=0.5, l_{1,2}=7, l_{2,3}=8, l_{1,3}=2$, тоді відповідні коефіцієнти впливу:

$a_{1,1}=-0.32 ; a_{1,2}=0.64 ; a_{2,1}=-1.28 ; a_{2,2}=5.13 ; a_{3,1}=-0.36 ; a_{3,2}=1.47$.

Залежно від значень $p$ та $q$, можна отримати систему з різними впливами.

Нехай $p=-1, q=2.5, l_{1,2}=7, l_{2,3}=8, l_{1,3}=2$, тоді відповідні коефіцієнти впливу: 


$$
a_{1,1}=-2.20 ; a_{1,2}=4.40 ; a_{2,1}=-8.75 ; a_{2,2}=7.01 ; a_{3,1}=-2.54 ; a_{3,2}=2.03 \text {. }
$$

При збільшенні числа вузлів треба враховувати співвідношення між кількістю рівнянь у системі та числом невідомих. Якщо в моделі $n$ вузлів, то система типу (24) буде складатися з $2 n$ рівнянь, а коефіцієнтів властивостей $a_{i j}$ при вимірності ГЧС $N$ буде $2 N$. Тобто, при збільшенні числа вузлів система (24) може стати перевизначеною і не мати дійсних розв'язків. Наприклад, при $n \geq 4$ та $N=2$ кількість рівнянь перевищує кількість змінних. Система стає перевизначеною і в загальному випадку не має дійсних розв'язків. Для подолання цього протиріччя можна або прийняти за невідомі деяку кількість коефіцієнтів властивостей, або переходити до ГЧС більших вимірностей.

Розглянемо випадок моделі з чотирма вузлами (рис. 5).

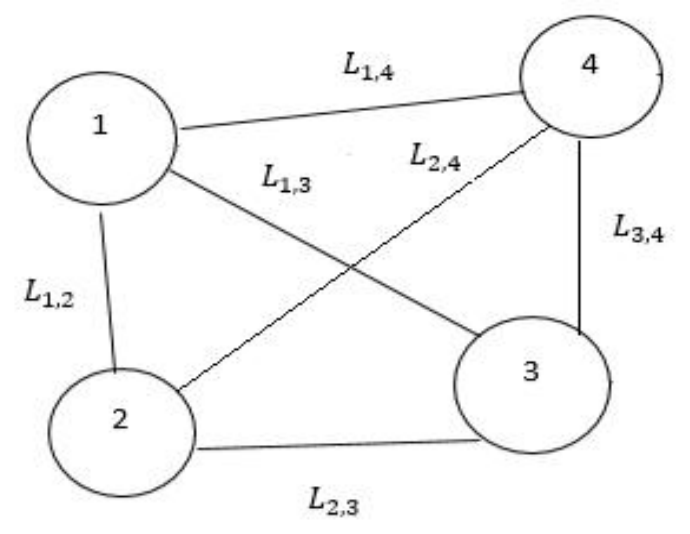

Рис. 5. Система з чотирма вузлами

Система рівнянь для системи з чотирма вузлами виглядає наступним чином:

$$
\begin{gathered}
a_{1,1} a_{2,1}+a_{1,2} a_{2,2} p=l_{1,2}, \\
a_{1,1} a_{2,2}+a_{1,2} a_{2,1}+a_{1,2} a_{2,2} q=0, \\
a_{1,1} a_{3,1}+a_{1,2} a_{3,2} p=l_{1,3}, \\
a_{1,1} a_{3,2}+a_{1,2} a_{3,1}+a_{1,2} a_{3,2} q=0, \\
a_{1,1} a_{4,1}+a_{1,2} a_{4,2} p=l_{1,4}, \\
a_{1,1} a_{4,2}+a_{1,2} a_{4,1}+a_{1,2} a_{4,2} q=0, \\
a_{2,1} a_{3,1}+a_{2,2} a_{3,2} p=l_{2,3}, \\
a_{2,1} a_{3,2}+a_{2,2} a_{3,1}+a_{2,2} a_{3,2} q=0, \\
a_{2,1} a_{4,1}+a_{2,2} a_{4,2} p=l_{2,4}, \\
a_{2,1} a_{4,2}+a_{2,2} a_{4,1}+a_{2,2} a_{4,2} q=0, \\
a_{3,1} a_{4,1}+a_{3,2} a_{4,2} p=l_{3,4}, \\
a_{3,1} a_{4,2}+a_{3,2} a_{4,1}+a_{3,2} a_{4,2} q=0 .
\end{gathered}
$$

Як видно з (25), система має 12 рівнянь, а невідомих лише 8. Тому намагання розв'язати ii відносно змінних var $:=\left[a_{1,1}, a_{1,2}, a_{2,1}, a_{2,2}, a_{3,1}, a_{3,2}, a_{4,1}, a_{4,2}\right]$ дає 
негативний результат, але якщо об'явити змінними, наприклад, ще 4 коефіцієнта впливу

$$
\operatorname{varl}:=\left[a_{1,1}, a_{1,2}, a_{2,1}, a_{2,2}, a_{3,1}, a_{3,2}, a_{4,1}, a_{4,2}, l_{2,3}, l_{1,3}, l_{2,4}, l_{1,4}\right],
$$

то одержимо розв'язки, які можна аналізувати:

$$
\begin{gathered}
a_{1,1}=-\frac{1}{2} a_{1,2} q, a_{1,2}=a_{1,2}, a_{2,1}=-\frac{2 l_{1,2} q}{a_{1,2}\left(q^{2}+4 p\right)}, \\
a_{2,2}=\frac{4 l_{1,2}}{a_{1,2}\left(q^{2}+4 p\right)}, a_{3,1}=-\frac{2 q l_{3,4}}{a_{4,2}\left(q^{2}+4 p\right)}, \\
a_{4,1}=-\frac{1}{2} a_{4,2} q, a_{4,2}=a_{4,2}, l_{2,3}=\frac{4 l_{1,2} l_{3,4}}{a_{4,2} a_{1,2}\left(q^{2}+4 p\right)}, \\
l_{1,3}=\frac{a_{1,2} l_{3,4}}{a_{4,2}}, l_{2,4}=\frac{l_{1,2} a_{4,2}}{a_{1,2}}, \\
l_{1,4}=\frac{1}{4} a_{1,2} q^{2} a_{4,2}+a_{1,2} a_{4,2} p .
\end{gathered}
$$

Нехай $p=1, q=0.5, l_{1,2}=7, l_{2,3}=8, l_{3,4}=2, a_{4,2}=3$, тоді отримуємо відповідні коефіцієнти впливу

$$
a_{1,1}=-0.16, a_{1,2}=0.64, a_{2,1}=-2.57, a_{2,2}=10.59, a_{3,1}=-0.15, a_{3,2}=2, a_{4,1}=-0.75
$$

та зв'язки

$$
l_{1,4}=2.04, l_{2,4}=32.81, l_{1,3}=0.42, l_{2,3}=6.86 .
$$

Нехай $p=-1, q=2.5, l_{1,2}=7, l_{2,3}=8, l_{3,4}=2, a_{4,2}=3$, тоді отримуємо відповідні коефіцієнти впливу

$$
a_{1,1}=-1.10, a_{1,2}=4.40, a_{2,1}=-1.41, a_{2,2}=2.82, a_{3,1}=-0.29, a_{4,1}=0.75
$$

та зв'язки

$$
l_{1,4}=2.04, l_{2,4}=4.77, l_{1,3}=2.93, l_{2,3}=8.29 \text {. }
$$

\section{Висновки}

Розглянуто приклади побудови складних мереж. У представлених мережах ребра відповідають взаємним впливам вузлів, у кожному з яких є декілька видів активності. Також розглянуто два види активності, що відповідають гіперкомплексним числовим системам другої вимірності, що ізоморфні систем $\Gamma_{5}(f, 2)$ залежно від значення виразу $p+\frac{q}{4}$. Проведено моделювання роботи мережі за допомогою гіперкомплексних числових систем і засобів ПКГО. Завдяки засобам ПКГО 
можна побудувати складну мережу будь-якої вимірності з декількома видами активності. Дослідження систем з більшою кількістю активностей залежить від потужності обчислювальної системи, на якій може бути встановлений ПКГО.

1. Blanchard Ph., Volchenkov D. Random Walks and Diffusions on Graphs and Databases: An Introduction (Springer Series in Syn-ergetics). Berlin-Heidelberg: Springer-Verlag, 2011.

2. Lovasz L., Winkler P. Mixing of Random Walks and Other Diffusions on a Graph. Surveys in Com-binatorics (ed. P. Rowlinson). London Math. Soc. Lecture Notes Series 218. Cambridge Univ. Press., 1995. P. $119-154$.

3. Кузнецов О.П., Жилякова Л.Ю. Двусторонние ресурсные сети - новая потоковая модель. Доклады Академии Наук. 2010. Т. 433. № 5. С. 609-612.

4. Жилякова Л.Ю. Сетевая модель распространения нескольких видов активности в среде сложных агентов и ее приложения. Онтология проектирования. 2015. Т. 5. № 3(17). С. 278-295

5. Ланде Д.В. Аналіз інформаційних потоків у глобальних комп'ютерних мережах. Вісник НАН України. 2017. № 3. С. 46-54.

6. Ланде Д.В., Ліненко Ю.О. Обмеження доступу до Інтернету у світі: мережева модель. Інформаційне право: сучасні виклики і напрями розвитку: Матеріали першої науково-практичної конференції / упоряд.: В.М. Фурашев, С.Ю. Петряєв (18 жовтня 2018, Київ). Київ: Національний технічний університет України «Київський політехнічний інститут імені Ігоря Сікорського», 2018. C. 50-54.

7. Kemple D., Kleiberg J., Tardos E. Maximizing the Spread of Influence through a Social Network. Proc. Of 9-th ACM SIGKDD Int. Conf. on Knowledge Discovery and Data Mining. 2003. P. $137-146$.

8. Granovetter M. Threshold Models of Collective Behavior. American journal of Sociology. 1978. Vol. 83. No. 6. P. 1420-1443.

9. Watts D.J. A Simple model of global cascade on random networks. Proc. Nat. Acad. Sci. USA. 2002. 99(9). P. 5766-5771.

10. Goldenberg J., Libai B., Muller E. Talk of the Network: A Complex Systems Look at the Underlying Process of Word-of-Mouth. Marketing Letter. 2001. No. 2. P. 11-34.

11. Губанов Д.А., Новиков Д.А., Чхартишвили А.Г. Социальные сети: модели информационного влияния, управления и противоборства. Москва: Физматлит, 2010. 228 с.

12. Калиновский Я.А., Бояринова Ю.Е., Сукало А.С. Гиперкомплексные числовые системы четвертой размерности. Киев: ИПРИ НАН Украины, 2017. 125 с.

13. Синьков М.В., Бояринова Ю.Е., Калиновский Я.А. Конечномерные гиперкомплексные числовые системы. Основы теории. Применения. Киев: ИПРИ НАН Украины, 2010. 388 с.

14. Калиновский Я.А., Бояринова Ю.Е., Хицко Я.В. Гиперкомплексные вычисления в MAPLE Киев: ИПРИ НАН Украины, 2020.180 с.

15. Калиновский Я.А., Бояринова Ю.Е. Высокоразмерные изоморфные гиперкомплексные числовые системы и их применения. Киев: ИПРИ НАН Украины, 2012. 183 с.

16. Калиновский Я.А., Бояринова Ю.Е., Хицко Я.В., Сукало А.С. Программный комплекс для гиперкомплексных вычислений. Электронное моделирование. 2017. Т. 39. № 5.С. 81-96. 